\title{
TERRA FÉRTIL, BOM SELVAGEM: HISTÓRIAS DO MAL-ESTAR
}

\author{
Lucia Helena
}

\begin{abstract}
RESUMO: Ce texte propose une lecture des romans "indigènes" de José de Alencar à partir d'un croisement de quelques hypothèses illuministes et de concepts plus actuels d'histoire, de culture et de nation. Il refuse les points de vue d'une critique idéologique plus récente et reafirme l'ambigüité propre au littéraire, qui permet d' inscrire la fiction de Alencar dans un espace textuel mouvant, necéssaire à la répresentation d'une histoire en proccès. Par cette voie, dans ces romans de Alencar, on peut lire, à côté de la mémoire du genocide, le renforcement d'une mémoire de la culture sauvage et la valorisation du naturel. En refusant les interpretations figées, cette lecture s'ouvre à la figuration du residuel, des déplacements et des intersections propres à l'etablissement des communautés imaginaires, aux récits de fondation et à une sorte de "pedagogie du désir d'être nation".
\end{abstract}

PALAVRAS-CHAVE: José de Alencar, romances indianistas, Literatura Brasileira, nação, história, memória, esquecimento.

O nacionalismo precisa ser compreendido ao ser associado não com ideologias politicas constrangidamente mantidas, mas com grandes sistemas culturais que o precederam e a partir dos quais - assim como contra os quais - ele passou a existir. '(ANDERSON, 1990 (1983), p. 19). ${ }^{1}$

Na fronteira do século XVIII para o XIX, a idéia de nação ganha sentido inteiramente novo e os crioulos do "novo mundo" não representam mais a si mesmos como participantes de comunidades paralelas e comparáveis às da Europa. É sob o impulso desse movimento transformador que surgem na América as sementes das narrativas de fundação que, ancoradas na utopia, carregam considerável complexidade na aparente trivialidade de seu conteúdo.

Na Europa, seu personagem-matriz seria Robinson Crusoé, náufrago a erguer na ilha deserta, com os despojos da civilização e a relação hierárquica e

Lucia Helena é professora de Literatura Brasileira da UFF.

${ }^{1}$ Há tradução brasileira, sob o título Nação e consciência nacional, 1989. 
escravagista com o indígena Sexta-feira, uma outra sociedade. No Brasil, para construir a imagem do homem empreendedor, pactário do novo contrato social, seria necessário "exumar os mortos". Narrativas históricas e indianistas, ou ainda mesclando as duas estratégias, desenterram o indígena, símbolo da terra virgem, para em seu nome alegorizar a comunidade possível na qual se erguerá a "mairi dos cristãos". Nessa construção, um elemento complicador se apresenta aos escritores: passada a relação colonial, permanecem em terra firme os herdeiros espirituais e carnais dos conquistadores. Enquanto isso, paradoxalmente, falta-lhes o diálogo com algumas potentes matrizes críticas da inscrição da modernidade desde Rousseau, já que a discussão sobre a subjetividade e sobre a coletividade permanece velada à problematização maior dos ideais lusitanos que ainda recortam o fato narrado. $\mathrm{O}$ novo homem brasileiro será, portanto, fruto de uma cultura híbrida, em que a mestiçagem se lança como um véu que encobre a ainda hierárquica medição de forças culturais. O destino de uma raça será romanticamente recontado e forjado, no esboço ao mesmo tempo eufórico e melancólico de uma nação.

A fortuna crítica hoje acumulada sobre estas ficções tem-nas considerado ineficientes, ideologicamente comprometidas com o ponto de vista do homem branco, que seria preservado pelas elites do século XIX brasileiro. Mas creio que esta visão merece ser urgentemente revista, pois ela pressupõe que entre a narrativa e a história haveria o peso de uma verdade que passam a cobrar da arte, sem se darem conta de que, todavia, esta a ultrapassa.

Em que pese a presença da História nos temas que abordam, as narrativas de fundação pertencem ao campo do literário. Em seu texto acolhem necessária e produtivamente a ambigüidade, ali mesmo onde as sociedades e o historiador querem (e talvez precisem) bani-la. Ao reordenarem ficcionalmente os sistemas lógicos e os paralelismos referenciais, estas narrativas podem falsificar, exagerar, burlar e exibir a impossibilidade de estabelecer balisas "verdadeiras", já que não constituem, como a História, enunciados regidos pelo critério de verdade. A narrativa de fundação não é, portanto, erro ou engano inconsciente ou propositado, nem falso testemunho, perjúrio ou espaço de veiculação de mera ideologia conservadora.

Em primeiro lugar, porque o que anunciam é uma concepção produtora de uma outra idéia de comunidade e de mundo. Segundo, porque põem em circulação figurações imaginárias de possíveis formadores da construção de um projeto de nacionalidade, ou de vários e distintos projetos que se entrecruzam e configuram elos comuns, que administram a rede de tendências e interesses divergentes em torno dos quais as comunidades "reais" se estruturam: unidade, limite, soberania territoriais e, por vezes, uma língua comum, além de uma concepção moderna e linear do tempo, questões a que Benedict Anderson longamente remete em seu Imagined Communities.

É próprio às ficções que participam desse "princípio de nacionalidade" ${ }^{2}$ construirem-se numa zona fantasmática do pensamento, em que se tocam e trocam a História e a lenda. E demandam uma leitura, até hoje ainda não realizada, fora de um

${ }^{2}$ Cf. HOBSBAWM, 1986, p. 101. 
interesse meramente ideológico. Em seus textos, o indígena, seja ele Peri, Poti ou Iracema, representa o locus de uma autoctonia, a terra e a raça pré-nacionais, e recua à condição de barreira, fronteira no interior de alguma coisa ameaçadora e caótica, força de desagregação - "memória" de uma terra selvagem e temida. E isto porque o processo ficcional das denominadas "narrativas de fundação" trabalha não só com o dito, a referência e o dizer, mas também com o silêncio, o não-dito e o que se diz sem querer dizer. É de sua natureza conviver com a pluralidade e a complexidade do hibridismo, sem fazer tábula rasa das ruínas deixadas pela colonização.

Tais narrativas simulam a criação de uma origem no tempo e no espaço, na etnia e nas classes sociais. Geram uma suposta origem na linha da temporalidade e esboçam a configuração da cor local, conferindo espacialidade à imaginação. Sugerem ainda a conciliação de interesses divergentes e até antagônicos, muitas vezes recorrendo ao tecido de uma "estória" de amizade e/ou de amor entre contrários.

As comunidades imaginadas seriam, portanto, atos discursivos que, quando têm sucesso,

“[...] produzem uma verdade cujo poder se impõe às vezes para sempre: a posição de uma fronteira, a instauração do Estado são sempre violências performativas que, se as condições da comunidade internacional o permitem, criam o direito (...). Para o melhor e o pior, a dimensão performativa faz a verdade, como diz Agostinho. Impõe, portanto, sua dimensão irredutivelmente histórica à veracidade tanto quanto à mentira." (DERRIDA, 1996, p. 21)

Até o momento, a crítica literária brasileira, ao formular a interpretação, hoje dominante, de que a obra de Alencar é conservadora, não tem levado suficientemente em consideração aspectos relevantes dessa produção, tais como o fato de que o narrador por ele construído desdobra-se num perfil ambíguo e dilemático. Por um lado, porta em si a marca intelectual iluminista da promessa de redenção pela utopia, que em nosso Romantismo desdobra-se sob a forma de uma conciliação não necessariamente conservadora, mas pedagogicamente tática na sua recepção e historicidade. Por outro, como ocorre nas páginas finais de $O$ Guarani, em que se narra a impossibilidade de Peri transpor a barreira civilizatória, abre a vertente de um Romantismo melancólico e problematizador, sob o qual se formula a hipótese, trágica, de que resta a Peri apenas um movimento para dentro de si mesmo e da natureza que ele, de certa forma, reduplica. Resta-lhe, como será também o destino de Iracema, refluir ao indiferenciado, confundir-se com a natureza que, se os concebeu, também os retém e, num certo sentido, engolfa-os em seus domínios. Recria-se, por desdobramento, a diferença imposta pelo pacto social do Estado-nação recém formado: a distinção entre os poderosos (civilizados e brancos) - os donos dos domínios, e a terra virgem, pujante e ameaçadora dos dominados, redenominados "selvagens", "cativos", "escravos".

Nos últimos vinte anos, a maior parte da fortuna crítica de Alencar reservou um lugar incômodo à sua ficção. Segundo o consenso, ele teria produzido uma idéia de nação retilínea e uniforme; partido de uma visão da história como continuum; 
apreendido a questão da nacionalidade sob o foco de uma luminosidade grandiloqüente e totalizadora; além de concebido a identidade nacional como uma essência atemporal e originária.

Sob esta perspectiva, seus romances têm sido lidos, a exemplo de Iracema, ora como um complexo sacrificial que emerge de uma não suficientemente feliz tentativa de escrever a história dos indígenas a contrapelo, vincando-a no ponto de vista do colonizado; ora como se a história da virgem dos lábios de mel reeditasse no enredo as tramas dos romances europeus coevos, fazendo da protagonista brasileira uma espécie de "irmã de incontáveis Clarissas e mesmo da já tardia Tess dos D'Ubervilles", o que levaria a heroína "a morrer de amor, depois de ter entregado corpo e alma ao sedutor branco, que então passa[ria] a desdenhá-la[...]", num "romance onde todos os índios não só têm alma branca mas também fenótipo branco [...]", e acreditando que a protagonista Iracema represente, simbolicamente, "a civilização indígena que se entrega ao conquistador branco, morrendo por causa disso" (GALVÃO, 1979, p. 385).

É oportuno reinvestigar ao que nos levam estas concepções, hoje tão difundidas, e uma outra que a elas se interliga - a de que personagens indígenas, como Peri, seriam, ao mesmo tempo, tão nobres "quanto os mais ilustres barões portugueses que haviam combatido em Aljubarrota ao lado de Mestre de Avis, o rei cavalheiro, [...]" e tão servos, como o "[...] servo espontâneo de Cecília, a quem [ Peri] chama Uiára, isto é senhora." (BOSI, 1992, p. 190).

Talvez o ineditismo de Alencar esteja exatamente na reverberação de uma relação ambígua entre a sociedade, o Estado e a felicidade de seus personagens, sempre ameaçada, ainda que sob a forma da liberdade imaginada no natural, até então visto, pela tradição portuguesa de leitura do Brasil, como o espaço de uma selva selvagem, pouco hospitaleira e ameaçadora. A grandeza da terra brasileira, funciona, em Alencar, ora como antídoto do complexo de colonizado, ora como força em que se trava um perpétuo conflito entre a natureza e a civilização, entre projetos culturais distintos e, àquele momento, inconciliáveis.

Há, nos romances de fundação de Alencar, os ecos de Montaigne e, por derivação, do próprio Rousseau, numa postura de revisão antropológica da leitura oficial e antiga dos cronistas sobre a barbárie do selvagem das Américas, que resulta corrigida por uma versão mais densa do indígena. Sobre isto, diz Alencar na "Advertência" de Ubirajara:

Homens cultos, filhos de uma sociedade velha e curtida por longo trato de séculos, queriam esses forasteiros achar nos indígenas de um mundo novo e segregado da civilização universal uma perfeita conformidade de idéias e costumes. Não se lembravam, ou não sabiam, que eles mesmos provinham de bárbaros ainda mais ferozes e grosseiros do que os selvagens americanos.

"Desta prevenção não escapavam muitas vezes espíritos graves e bastante ilustrados para escreverem a história sob o ponto de vista mais largo e filosófico.” (ALENCAR, 1965 , p. 269) 
A novidade de Alencar implica trazer para o cenário da cultura brasileira uma versão da instituição social baseada não na depreciação, mas no revigoramento da memória da cultura dita selvagem, embora ele não possa, conjunturalmente, afastá-la de outra cena histórica, recalcada. Por isso, num certo nível, o relevo à cultura indígena esbarra na incômoda memória (a ser esquecida) do genocídio praticado contra os índios.

Será, então, numa ficção que forja o esquecimento, pela fundação de uma origem lendária em que a História se torna fábula, e será, também, pelo deslocamento dos personagens (brancos e/ou indígenas) para as forças da terra, que este dado de valorização do natural mais consistentemente se inscreverá com dramaticidade pungente, tanto na morte de Iracema quanto no deslizar incerto de Peri e Ceci sob as águas do dilúvio.

Forças da natureza e da terra-paisagem são animizadas ao longo das narrativas de fundação, e só superficialmente poderiam ser tidas como exóticas, devendo, a contrapelo, ser repensadas como protagonistas-fantasma de um pacto social e político colonial que, ao mesmo tempo em que se rompe, recusa-se a deixar-se romper, mergulhando o espaço romanesco na magnitude das águas do Paraíba e do Paquequer, em $O$ guarani, e na sensualização do tronco da palmeira, tanto em Iracema, quanto em As minas de prata (ALENCAR, 1964, p. 286), tudo isso se construindo a partir de uma tensa relação entre a solidão, a memória e o esquecimento em que acabam por mergulhar também os personagens, algumas vezes engolfados em tematizações que reengendram bíblicos dilúvios de purificação.

Contrariamente à concepção vulgar de linearidade da história, a escrita dos três romances em que o indígena se destaca presta-se a favorecer que Alencar demonstre ao leitor que seu projeto é um texto em mudança, que se vai transformando em direção a idéia mais aberta do selvagem e de seu mundo sem Estado, transmudados ambos numa figuração da comunidade de Estado-nação.

Vale que nos lembremos aqui do batizado de Poti e de sua conversão, em Iracema e, n' O guarani, da situação de Peri, impedido de ir para a cidade, e tendo como mediador e terceiro termo a amizade de Ceci, representante da casa e do senhor de Mariz, na qual, muito mais do que as relações com a Idade Média, tão propaladas pela crítica, fulgura uma figuração dos estados-nação.

Pode-se assim dizer que a ambigüidade ronda a idéia de nação e de nacionalidade em Alencar, ao contrário do que tem sublinhado a crítica. Essa ambivalência brota da consciência crescente, que ele demonstra ter, de que a temporalidade cultural da nação inscreve uma sociedade em transição, em que o nacionalismo não é entendido lado a lado com ideologias políticas, mas com grandes sistemas culturais que o precederam e a partir dos quais, e algumas vezes contra os quais, passou a existir.

Assim como seu texto, em que são palpáveis transições - algumas já aqui indicadas, no cotejo da configuração do entendimento da sociedade indígena, que difere de $O$ guarani para Ubirajara, a história social em que o romance "indianista" de Alencar se insere não está pronta, mas em processo. Esta labilidade necessita ser 
levada em conta pela crítica, que se vê diante de uma estória sendo tecida entre a memória e o esquecimento da História, o que pode favorecer a busca de interpretações menos holísticas do que as que têm sido apresentadas acerca da obra do autor. Interpretações que, de certo modo imobilizam e congelam num significado fechado o processo de significação que se opera, fluidamente, no texto de Alencar, muitas vezes por ele mesmo revisto e anotado, de um romance a outro, num traçado cambiante, movediço, de volume a volume.

A incidência de leituras extremamente ideológicas do texto de Alencar indica uma carência da crítica, e não do texto em si, ainda que a estes se possam fazer observações sobre seus contra-sensos ${ }^{3} \mathrm{e}$ inacabamento. Mas a sensação de mal acabado, que é como o inacabamento se manifesta em alguns de seus textos, é mais um índice do modo de ser em processo de sua ficção. Isto porque escrever a nação, em Alencar, é inscrever, pela textualização, a nação sob a égide do residual, dos elementos em deslocamento, construindo personagens que indicam deslocamentos e intersecção de padrões e comportamentos não só europeus, nem só brasileiros.

A obra de Alencar encontra uma forma de, simultaneamente, articular o esquecimento/a lembrança do mito do bom e do mau selvagem, do bom e do mau colonizador, e de inscrever, como História "pátria", esta mitologia "reformulada", fundadora de uma hipótese do nacional que tentava se tornar hegemônica e que, a cada releitura da crítica, tem contado com novas recepções e "reformulações". E que tanto se instalou no imaginário cultural brasileiro a ponto de, ainda hoje, a seus veios retornarem ecos, simulacros e distorções daquele processo imaginarizante, para o bem e para o mal.

Homi Bhabha refletindo sobre o nacionalismo, encorpa meu argumento:

"O discurso do nacionalismo não é minha principal preocupação. Desta forma estou tentando escrever contra a certeza histórica e a natureza estabelecida desse termo e a respeito da nação ocidental com uma forma obscura e onipresente de viver a localização da cultura. Esta localização está mais em torno da temporalidade e menos sobre a historicidade, é uma forma de viver mais complexa do que "comunidade", mais simbólica do que "sociedade", mais conotativa do que "país", menos patriótica do que pátria, mais retórica do que a razão de estado, mais mitológica do que ideológica." ( BHABHA, 1990, p. 291-292 - Tradução nossa e grifos do autor.)

Deste modo, a sistemática escolha do autor de trabalhar miticamente o material da História para narrar o seu indianismo pode ser não uma forma um tanto sorrateira de escamotear sua ideologia conservadora, mas o modo pelo qual, com admirável competência narrativa, Alencar indica e compreende a própria natureza "mitológica" e ficcional do discurso do nacionalismo. Além, é a manifestação da consciência de que a idéia de nação, construída no último quartel do XIX, entra em conflito com o contingente de signos e de símbolos arbitrários que representam a vida afetiva de uma cultura nacional.

${ }^{3}$ Cf. SCHWARZ, 1981. 
A vontade de construir a nação e a necessidade de esquecer o horror dos genocídios, de que é herdeiro o intelectual romântico do oitocentos, são signos fundamentais tanto da construção quanto da leitura da ficção de Alencar. Através deles se mobilizam símbolos de afinidade entre o que não é afim: raças diversas, projetos econômicos divergentes, interpenetração de temporalidades e sublimação de interesses em conflito e de hierarquias implantadas pela estratégia da colonização e, a posteriori, pela adoção dos princípios do liberalismo "fora do lugar", que lhe era contemporâneo.

Tudo isto faz da obra de Alencar, e refiro-me em especial aos três romances ditos indianistas e históricos - O guarani, Iracema e Ubirajara -, uma espécie de pedagogia da vontade de ser nação na qual, ao contrário de vítimas sacrificiais, constroem-se personagens necessariamente rasas para que possam carregar, sem desequilíbrio maior, uma instabilidade fundadora. Personagens através dos quais se pode recordar e esquecer, enquanto formas liberadoras de identificação nacional, a memória da História, para reconstrui-la na fábula de um texto cuja vocação fundamental é parecer que re-inaugura, no tempo imemorial da lenda, a comunidade imaginada possível para uma sociedade contraditória, não harmônica e não liberal.

Reler, hoje, os percalços da obra de Alencar e de sua fortuna crítica significa, dentre outras coisas, compreender que o interesse pela reflexão sobre o nacionalismo, em suas manifestações de atenção às particularidades, ao local e à diferença cultural, surge como possível reação a dois componentes da modernidade que se encontram associados de forma estreita à globalização: a dúvida radical e a fragmentação ${ }^{4}$.

\section{BIBLIOGRAFIA}

ALENCAR, José de. Iracema e Ubirajara. In: . Obra completa. Rio de Janeiro, Aguilar, 1965. v. III.

. O guarani e As minas de prata. In: . Obra completa. Rio de Janeiro, Aguilar,

1964. v. II.

. Iracema, lenda do Ceará. ed. Silviano Santiago. Rio de Janeiro, Francisco Alves, 1978.

. Cartas de Erasmo. In: _. Obra completa. Rio de Janeiro, Aguilar, 1960. v. IV. ANDERSON, Benedict. Nação e consciência nacional. São Paulo, Ática, 1989. . Imagined Communities. Reflections on the Origin and Spread of Nationalism. London, Verso, 1990 (1983).

. Memória e esquecimento. Apostila mimeo. Traduzido por Maria Helena Rouanet [s.ed.] [s.d.].

BHABHA, Homi. Dissemination: time, narrative, and the margins of the modern nation. In: (org). Nation and Narration. London and New York, Routledge, 1990.

${ }^{4}$ Cf. GUIBERNAU, 1997, p. 143-150. 